\title{
The subjective experience of psychotherapists during moments of rupture in psychotherapy with adolescents
}

\author{
Javier Morán, ${ }^{1-3}$ M. Francisca Díaz, ${ }^{1}$ Claudio Martínez, ${ }^{2,4}$ Carlos Varas, ${ }^{1}$ Roxana Parra Sepúlveda ${ }^{5}$ \\ ${ }^{1}$ School of Psychology, University of Valparaíso, Valparaíso, Chile; ${ }^{2}$ Millennium Institute for Depression and Personality Research \\ (MIDAP), Chile; ${ }^{3}$ Faculty of Medicine, University of Chile, Santiago, Chile; ${ }^{4}$ Faculty of Psychology, "Diego Portales University", \\ Santiago, Chile; ${ }^{5}$ Student Wellbeing Service, Kingston University, London, UK
}

\begin{abstract}
The study of the ruptures of the therapeutic alliance has impacted research in psychotherapy by highlighting the relational nature of this phenomenon. Despite ruptures are frequent and relevant during adolescent psychotherapy, most of the empirical evidence in this field has been carried out with adults. Understanding the subjective experience of the therapist during ruptures while working with adolescent is proposed as a starting point for the study of this type of interactional scenarios. The study examined the meanings that emerge from the therapists' experience in terms of their explanations about the causes and effects of ruptures with adolescents. Eight psychotherapists were interviewed about their experiences during ruptures with young patients. The data was qualitatively analyzed through the Interpretive Phenomenological Analysis method. Four categories emerged: the failure to recognize the adolescent's experience, the intensity of the affective experience of adolescents in psychotherapy, therapeutic boundaries as an articulator of the therapeutic purpose and, the obstacles that family generates during the therapeutic process. This study concurs with the literature on the need to make explicit with the family about the meaning, roles and limits of the therapy, and to prevent the exercise of control from an adultcentered position. It is concluded that in order to avoid and repair ruptures with adolescents in psychotherapy, an approach that integrates a sensitive attitude, an ecological point of view and mentalizing about the origin of the rupture is needed.
\end{abstract}

Key words: Therapeutic alliance; Adolescent psychotherapy; Alliance ruptures; Qualitative methods.

Acknowledgements: the authors would like to thank professor Jeremy Safran for his generous contribution during the writing of this article.

Funding: this work was supported by the National Commission for Scientific and Technological Research (CONICYT) National $\mathrm{PhD} / 2014$ - 21140172 scholarship; the National Fund for Scientific and Technological Development (FONDECYT) Project $\mathrm{N}^{\circ} 1150639$; Fund for Competitiveness (Fondo de Innovación para la Competitividad, FIC), part of the Ministry of Economy, Development, and Tourism, through the Millennium Scientific Initiative (Project IS130005).

Received for publication: 21 November 2018.

Revision received: 18 January 2019.

Accepted for publication: 22 January 2019.

This work is licensed under a Creative Commons Attribution NonCommercial 4.0 License (CC BY-NC 4.0).

CC Copyright J. Morán et al., 2019

Licensee PAGEPress, Italy

Research in Psychotherapy:

Psychopathology, Process and Outcome 2019; 22:34-44

doi:10.4081/ripppo.2019.346

\section{Introduction}

In the last decades, research in psychotherapy has produced a significant body of empirical evidence that has positioned therapeutic alliance as a main factor in explaining therapeutic change (Horvath, Del Re, Fluckinger, \& Symonds, 2011; Lambert, 2013). Despite the fact that this association has been described as modest (Horvath \& Bedi, 2002), in the present, therapeutic alliance is consistently considered to be the most robust and reliable variable when investigating the relationship between the psychotherapeutic process and its outcomes (Krause, Altimir, \& Horvath, 2011), and it is even deemed, by some authors, as a therapeutic goal in itself (Roth \& Fonagy, 2013).

In spite of the fact that most of the evidence tends to come specifically from research on adults, in studying psychotherapy with adolescents, the role of therapeutic alliance has increasingly proven to be a key factor facilitating ther- 
apeutic change; as it is, it seems to play an even more critical role in this target context than in psychotherapy with adults (Bhola \& Kapur, 2013) as there is often the need to deal with it throughout the therapeutic process due to the common relational difficulties characterizing interventions with young people (Shirk, Karver, \& Brown, 2011). Nonetheless, most literature suggests not to extend the findings obtained from studies on adults to interventions with adolescents, as interventions with the latter population are highly susceptible to the developmental particularities of this life stage. Furthermore the findings of previous researches report that psychotherapy with adolescents tends to be characterized by, among others, a significant influence of the family over the course of the treatment (Hawley \& Weisz, 2003), the existence of a generally external motivation to participate in psychotherapy (DiGiuseppe, Linscott, \& Jilton, 1996), the presence of multiple sources of information besides the adolescents themselves, such as family and school (Achenbach, McConaughy, \& Howell, 1987), the tendency of therapeutic alliance with adolescents to be weaker and more unstable than that with adults (Horvath et al., 2011) and the need for therapeutic alliance to be developed both with the adolescent and with other members of the family system (Shirk et al., 2011).

All the above aspects in addition to the multiple changes experienced by adolescents on a psychological, biological and social areas of development (Delgado, Strawn, \& Pedapati, 2015; Steinberg et al., 2006) shape a complex scenario that challenges clinicians while attempting to establish a therapeutic alliance.

As a way to respond to the evident need to deepen the research on therapeutic alliance during the 90s, Safran (1993) and Safran and Muran (1996) developed a theoretical proposal based on relational psychoanalysis that has turned out to be a relevant contribution to the traditional monadic perspectives in psychotherapy, which have shown a tendency towards the evaluation of the events taking place in psychotherapy through the use of pre-post designs, without taking into account the mutual influence phenomenon between therapists and consultants during the process (Gelo, Pritz, \& Rieken, 2015). The contribution of these authors has become an important referent which has encouraged the development of relational research in psychotherapy (Horvath, 2016). Safran and Muran (2000) highlight the relational process articulated at the very foundation of therapeutic alliance, conceiving the therapeutic relationship as an ongoing process of intersubjective negotiation between client and therapist. This process is characterized by the presence of moments of tension and deterioration in the quality of the alliance, known as "ruptures", and moments in which this tension seeks to be resolved, known as "resolutions" (EubanksCarter, Muran, \& Safran, 2014). Ruptures vary in intensity, duration and frequency, depending on every particular dyad, but they are described as situations that inevitably occur in the course of the therapeutic process and, although their occurrence may increase the risk of early withdrawal from treatment, its resolutions and elaboration may be significantly connected to therapeutic change (Safran, Muran, \& Samstag, 1994).

This model of ruptures and resolutions has been scarcely, and only recently, applied to research on psychotherapy with adolescents. However, it has shown to be useful in the clinical work with this client group.

For example, Daly, Llewelyn, McDougall, and Chanen (2010) studied a group of 86 adolescents diagnosed with borderline personality disorder; found that in the process of resolution of ruptures, in cases where the therapists followed all phases of their task-analysis model, they obtained better therapeutic results. A more recent study (Gersh et al., 2017) used a sample of 44 adolescents; the researchers reported an inconsistent association between the resolution of ruptures and the therapeutic outcomes, although the resolution of ruptures in later moments of the therapy was associated to the change, contrary to what the literature on adults reports (Safran, Muran, \& Eubanks-Carter, 2011). Finally, another study (Binder, Holgersen, \& Nielsen, 2008) exploring the actions performed by therapists working with adolescents in order to favor engagement with therapy and resolve ruptures evidenced the complex nature of treatment in these moments, revealing the intertwined articulation between the specific therapeutic actions required and the theoretical therapist's understandings of adolescent's development.

This type of interactive scenarios presents a complex challenge for clinicians who work with adolescents, yet it is significantly relevant for the progress of the therapeutic process (Binder, Moltu, Hummelsund, Sagen, \& Holgersen, 2011) and compels researchers to further develop this area of study (DiGiuseppe et al., 1996). A deeper understanding of the mutual influence that takes place in moments of rupture is central to such development and may be initially explored by means of a qualitative research. Therefore, the main objective of the present study is to characterised moments of rupture during therapy with adolescent clients from the therapist's perspective. Specifically, the main causes and effects of these disruptions are explored. In order to do so, special attention is paid to the specific interactional scenarios, accounting for the triggers and their display as rupture in the therapeutic alliance.

\section{Materials and Methods}

The study uses a qualitative design and seeks to explore the meanings that emerge from the therapists' experience, their explanations about the causes and effects of ruptures with adolescents in the relational context in which these occur. The analysis of the data is based on an adaptation of the Interpretive Phenomenological Analysis method (IPA, Pietkiewicz \& Smith, 2014). 
The IPA has been used for research in psychotherapy (Weitkamp et al., 2017; Wilson \& Sperlinger, 2004) as an inductive method to explore how people build meaning out of their life phenomena, recognizing the felt experience of the participants.

\section{Participants}

Eight clinical psychologists participated in this study. As an inclusion criterion, they were required to have at least 5 years of work experience as clinical psychologists with adolescents. As criteria of maximum variability of the sample, due to the exploratory nature of the study, the selected professionals were expected to have clinical experience in different areas and to do clinical work from different theoretical approaches, with at least two interviewees per approach (Table 1). The interviewees were selected by means of a snowball sampling process that favored the adaptation of the subjects to the inclusion criteria and maximum variability. The participants were directly contacted by the researchers. The appropriate number of interviewees was determined based on the IPA criteria (Pietkiewics \& Smith, 2014), the appropriate number of interviewees was determined. As this approach privileges the depth of the analysis, samples tend to be small, ideally ranging from 6 to 8 participants (Turpin et al., 1997).

\section{Data collection}

A semi-structured interview script was elaborated from the explicitation interview (Maurel, 2009) that aimed to facilitate the exploration of sequential elements (what happened next, what it implied), actions (what did you do, what did he do), affective elements (what did you feel), and reflexive elements (how that is explained, what you think happened to him) during rupture moments in adolescent's psychotherapy.

The interview was organized into four dimensions: i) Introductory questions, aimed to gain a deeper understanding of the interviewees' clinical experience with adolescents; ii)
General rupture questions, aimed to identify a rupture moment in a chosen therapeutic process and talk about its triggers, the actions to manage this moment and experiential aspects of it (I would like you to tell me, with as much detail as possible, about a situation in a psychotherapy process with teenagers in which you have experienced a rupture with. What do you think led to this situation? What do you think happened to your patient during the situation? What happened to you? What did you do during this situation?); iii) Specific rupture questions, aiming to explore the therapeutic interventions that aimed to cope with the rupture, its effects on the therapeutic process and therapeutic relationship (Was the rupture repaired? If the answer is positive: What causes do you think contributed to the positive outcome? What effects did this have on the therapeutic process and on the therapeutic relationship? If the answer is negative: How do you explain the fact that it was not possible to repair the rupture? What effects did this have on the therapeutic process and on the therapeutic relationship?) After that, the interviewees were asked to recount another rupture situation. If they first reported a situation of a repaired impasse, then they were asked to comment on a case in which the rupture was not repaired and vice versa; iv) Reflection questions, aiming to elicit a reflection about their therapeutic practice with adolescents in the context of dealing with ruptures (In both situations, would you have done anything different in your intervention if you have had the chance? If your patient had been an adult, do you believe that this situation would have been different? How? Why?). Later on, with the aim to elicit more spontaneous stories, they were asked to recount two more situations, one of a repaired rupture and another one of non-repaired rupture, repeating the same interview patterns from points 2,3 and 4 .

The interviews lasted approximately one hour, were recorded and transcribed; information about names and places that allowed the identification of the interviewees and their clients, were modified. All interviews were conducted by an infant-adolescent clinical psychologist who was trained in the application of this script by one of the main researchers. At the time of the interview each par-

Table 1. Characterization of the interviewees.

\begin{tabular}{lllllc}
\hline Therapist & Sex & Age & Clinical approach & $\begin{array}{c}\text { Years of clinical } \\
\text { experience with adolescents }\end{array}$ & Therapist's working setting \\
\hline 1 & Male & 43 & Systemic Family Therapy & 5 & Social services \\
\hline 3 & Male & 32 & Constructivism & 11 & Education \\
\hline 4 & Male & 36 & Constructivism & 11 & Primary care mental health \\
\hline 5 & Male & 37 & Psychodynamic & 7 & Education \\
\hline 6 & Male & 33 & Humanism & 11 & Education, Social services \\
\hline 7 & Female & 36 & Systemic Family Therapy & 9 & Primary care mental health \\
\hline 8 & Female & 37 & Psychodynamic & 40 & Primary care mental health \\
\hline
\end{tabular}


ticipant signed an informed consent that ensured confidentiality and anonymity. The study follows the ethics principles of the Declaration of Helsinki.

Each one of the eight interviews provided the narrative of four episodes of rupture, that is, 32 stories, accounting for 16 repaired episodes of rupture and 16 unrepaired episodes of rupture.

\section{Analysis}

The analysis of the interviews was carried out by two clinical psychologists, one of them was an MA student, and the other, a PhD student.

Topic identification was carried out following the steps proposed by Smith, Flowers, and Larkin (1999) for the IPA. First, a joint reading of a random interview was carried out, generating preliminary notes on first impressions and reflective comments, keeping the focus on both the content and the affects transmitted by the interviewee throughout each of the four rupture episodes. Later on, emergent notes were taken and then reformulated as conceptualized sentences using psychological terminology and, therefore, with a higher level of abstraction. These corresponded to the first emerging themes. Then, the same procedure was carried out for individual analysis of each of the remaining interviews, each time considering previous interview notes and including specific emerging elements from each interview. After these analyses, the coders discuss the emerging issues and reconcile differences through consensus.

A third phase consisted in categorizing emerging themes based on thematic similarities. Guiding questions were designed for the coders use based on the research objectives, with the aim of supporting the organization of merging themes in broader dimensions. The guiding questions are: i) Which therapeutic attitudes contributed to rupture; ii) Which therapeutic interventions contributed to rupture; iii) What are the patient's predispositions that combined with the therapeutic intervention, contributed to rupture; iv) What are the effects of rupture on therapists, patients and/or therapeutic relationships.

In this phase, issues that did not fit the emerging structures or that were too exceptional were excluded.

Throughout the process, a clinical psychologist supervisor was consulted by the team about emerging results and facilitated a reflective process with the team about the findings at a clinical level.

Once a final taxonomy of emerging subthemes was elaborated, were audited by a fourth specialist in qualitative methods.

\section{Results}

From the analysis of the interviews four categories emerged; they refer to interactive scenarios that characterize moments of rupture with adolescents. The following are the emerging categories, which are also summarized in a table that shows the emerging topics according to each dimension.

\section{Failure to recognize the adolescent's experience}

This failure is understood by the interviewees as lack of consideration for the adolescent's immediate experience convey by the adolescent, both at affect level ("I was not able to recognize at that moment what was happening to her" - Therapist 3) and content level ("I was asking him about other things, we did not agree on what we were talking about" - Therapist 6) or as moments when the adolescent patient's history and their previous experience were not being taken into account ("the first time I didn't know, but the second time I knew what I could do...and then I couldn't... think that was not handled very well" Therapist 4). This failure to consider the patient's experience is manifested during interventions that have been described as non-contingent and focused on the experience of the therapist, who frequently assumes an expert position, as one interviewee describes: "the ruptures with adolescents is because the therapist tries to tell something that is not the adolescent idea, but yours" - Therapist 1.

On the one hand, the interviewees mention in the reported stories certain evolutionary characteristics that are specific of adolescents; this explains why this type of interventions can be so sensitive and favor ruptures. These evolutionary characteristics include "a high sensitivity to the environment." As Therapist 5 states when comparing adolescents' and adults' psychotherapy: "the sense of awe that adolescents have, their continuous search for discovery, for questioning the world of adults". On the other hand, interviewees mention the low tolerance that young people show towards what they evaluate as "errors of their therapists". In this regard, another interviewee points out: "As an adult I go to therapy and sometimes it seems to me that the therapist is not that clever...I feel he asks me questions...I feel that sometimes he is not listening to me...but I still give him more opportunities. I feel that teenagers do not...maybe teenagers are more extreme in their assessment" - Therapist 2.

This type of interactions seems inevitable, not only because of the unpredictability of the consultants, but most of all because of the impossibility of the therapist to maintain a level of awareness and constant alert about the relational effect of all their interventions in a context of complex interaction.

A noteworthy element emerging from this type of impasse is the interviewees tendency to conceptualize ruptures with adolescents as a phenomenon for which therapists are responsible of: "He kind of like criticized me... and my explanation has to do with the fact that, in that moment, I was not able to identify what was happening to him... and for that reason.... uh...the fact of having tackled family issues with less care and time" - Therapist 1.

This type of situation usually has the consequence of 
consultants' refusal to refer to these topics in the future because they do not feel accepted or recognized: "What are you going to school for, what is the point of school... and then she reacted very badly, that is, -You do not understand any of this...you are an ally of the enemy, you try to justify the teacher... and the truth is that then it did not... it did not work out, I think I never got him to understand that I was talking about him, not about my values or views. I believe that I was never able to solve that impasse...in the end, the topic remained a closed compartment that was never touched again, and she never again spoke about academic issues"- Therapist 8 (Table 2).

\section{Intensity of the affective experience of adolescents in psychotherapy}

Affection plays a prominent role in interventions with adolescents, as described by the interviewees. Given the intensity with which adolescents experience their internal world, many of their ruptures tend to be characterized by the emergence of overwhelming emotions which in turn generate equally intense emotions in the therapists, who often express feelings such as tension, paralyzing anguish, confusion, fear or perplexity. As an interviewee exemplifies: "What I was trying to do with her...was...to calm down, because I realized that I was distressed and scared, and I realized that...I was scared that she would kill herself, yes, that was my fear... and I was trying...not to control my fright, but to regulate what my position in front of her was" - Therapist 7. This type of affection experienced by the therapist can be noticed by patients and contributes to create the expectation that they cannot be contained by the therapist: "I think he was very distressed, he noticed my anxiety and I was more distressed...he has this sense of guilt then...it was like this pattern...I raised topics that demanded... uh...to be in touch with distressing feelings...this boy was off school, and had presented some psychotic symptoms...then these symptoms began...and I was distressed and scared... he perceived that, he became more distressed..." - Therapist 1.

Therapists' actions taken to face these moments sometimes lead them to adopt a controlling position to promptly regulate the crisis. The following interviewee also comments on how these intense emotions led him to question his own performance: "I think this causes a lot of anguish...it causes a sense of inefficiency, doesn't it? I think the feeling of professional competence hurts a bit...because it's like...and you get anxious and you start to act hastily, and you commonly concretize more...like since we cannot go into that topic then let's talk about weight... How many times did you go out and exercise today?' or 'How many times did you get distressed? How many eating binges did you go on? How did you feel before the binges?'" - Therapist 1.

Another instance in which the emotional intensity of adolescent's experience becomes evident is in response to interventions where they are challenged, especially in the early stages when the therapist-patient bond has not yet been strengthened. In the case of adolescents, this type of actions, as pointed out by the interviewees, also favors the therapist positioning as an expert adult, close to a controlling parental role, which is strongly resisted by adolescents in psychotherapy. "Um...so...I stood firm in that position...and she started to get annoyed...she started to evidently behave as if she did not want to be there... to feel that I was taking a patronizing role, as if I were her mother, a desire to control her...to do everything against what we had been working on in the therapeutic process" - Therapist 4.

Finally, when addressing the issue of complex family dynamics, the therapist faces a highly emotion-charged intervention. In these circumstances, patients tend to withdraw from interaction. Therapists explain this behavior as their patients' lack of maturity to understand complex family dynamics or the fact that these dynamics can often be at the core of the problem. As one interviewee points out in explaining the constant reluctance of a teenage patient to talk directly about family conflicts linked to food: "I believe that she was in a moment when she was not able to put up with them emotionally (her family). She was able to worry about eating or not eating or exercising, but she did not have the psychological structure to take a more abstract leap. Their family relationships were too chaotic... an intermediate space was needed" - Therapist 7.

Table 2. Failure to recognize the adolescent's experience.

\begin{tabular}{ll}
\hline Guiding questions & Themes \\
\hline Which therapeutic attitudes contributed to rupture? & $\begin{array}{l}\text { Difficulty to maintain a level of awareness and constant alert regarding the adolescent's needs; } \\
\text { lack of consideration for the adolescent's immediate experience }\end{array}$ \\
\hline Which therapeutic interventions contributed to rupture? & $\begin{array}{l}\text { Non-contingent interventions with the patient's experience, control actions from an expert or } \\
\text { paternalistic stand }\end{array}$ \\
\hline $\begin{array}{l}\text { What are the patient's predispositions that combined } \\
\text { with the therapeutic intervention, contributed to rupture }\end{array}$ & $\begin{array}{l}\text { High sensitivity to the environment, low tolerance to "errors of the therapists", changing } \\
\text { nature of affection, need for autonomy. }\end{array}$ \\
$\begin{array}{ll}\text { What are the effects of rupture on therapists, patients } \\
\text { and/or therapeutic relationships }\end{array}$ & $\begin{array}{l}\text { Therapists blame themselves when they perceive patient's withdraw in response to a lack of } \\
\text { attunement or patients become avoidant to talk about topics in which they may have not felt } \\
\text { recognized or validated during the therapeutic process }\end{array}$ \\
\hline
\end{tabular}


A noteworthy element in the work with children and adolescents that several interviewees recurrently refer to is their role as children's rights protective agents. They tend to place themselves as caregivers and accountable for their patients' mental health, an element that makes ruptures particularly concerning in critical situations, therefore all this becomes a constant source of tension for clinicians. As one therapist argues: "When you think about suicide of teenagers and adults...they are different, but not because of the particular adolescent and adult, but because of the legal protection issues that underlie...right? Then children are objects of social protection... and one, as an agent working with minors, must always be watching over that...especially in terms of protection, when there is a therapeutic impasse that may affect the therapeutic bond, that is very complicated" - Therapist 5.

Repairing situations of intense adolescent affect experience during therapy would contribute to the strengthening of therapeutic alliance in this dimension more than in any other dimension. It is this bond that significantly contributes to the repair of other bonds. Another interviewee says: "When there is repair, there is repair of the bond". As Therapist 2 points out, this aspect would be even more relevant than when working with adults, "I feel that when working with teenagers the bond is more important...I believe that adults are willing to tolerate therapists that sometimes do not seem so sensitive to them."

It is worth to mention that most interviewees reported that therapeutic alliance is not an aspect that comes to be established at some point, but it becomes a permanent and unstable endeavor that is pursued throughout the psychotherapeutic process. Although it may be strengthened over time, considering it as an already consolidated element may lead to less attention to relational patterns that contribute to the emergence of ruptures. Moreover, a single rupture, despite the presence of a strong therapeutic alliance, could lead to the deterioration of the process and even to its anticipated termination, as illustrated in by the following vignette: "I had a disastrous example that ended up affecting a long and very positive process... and at the end of the process I did not expect something like this to happen...I started up with the feeling that there was reliability in our work interaction... an important concrete situation uh...I feel we threw away important work we had developed until then" - Therapist 5. In addition, the possibility of ruptures having the potential to be repaired is conditioned not only by the clinician's skills but also by an attitude of authenticity: "If you are not transparent, they begin to attribute bad intentions to you, to your questions or your activities...maybe not bad intentions, but more suspicious... as they are more...they are also wondering what the therapist thinks...uh...that may be more... there could be more difficulties arising from that" - Therapist 6 (Table 3).

\section{The therapeutic boundaries as an articulator of the therapeutic purpose}

The beginning of a therapeutic process with adolescents, as referred to by the interviewees, is usually motivated by third parties, thus becoming a space that represents an adult world that adolescents do not identify themselves with: "The disadvantages or difficulties...in general, they relate to the perception that teenagers have of a professional who is usually conceived as the enemy...that is, I hate my mom, the police, the teacher... and all grown-ups. "' Another interviewee adds: "The vast majority of children who consult, consult...not because of their own desire to do so...but because they had problems at school or because they fought with their parents or because...they smoked marijuana or because they committed a crime and their parents force them to go" - Therapist 8.

When an adolescent has not chosen to attend therapy, the process is started with low motivation, this is described by the interviewees as lack of confidence in the therapist's ability to really help them. One participant comments about how this is accentuated when adolescents have had previous therapeutic unsuccessful experiences that, in the adolescent's view, have proven psychotherapy to be a controlling space: "I believe that when he came he was in a state of distrust. I think he came to test maybe...to see what happens...because I feel that maybe... he actually told me later...that what had happened with the other two therapists and with the psychiatrist... he felt that those people were always trying to teach him,

Table 3. Intensity of the affective experience of adolescents in psychotherapy.

\begin{tabular}{|c|c|}
\hline Guiding questions & Themes \\
\hline Which therapeutic attitudes contributed to rupture? & $\begin{array}{l}\text { Consideration of the therapeutic alliance as a consolidated aspect, lack of regulation of one's } \\
\text { affections, assumption of a role of safeguarding the rights of children and adolescents }\end{array}$ \\
\hline Which therapeutic interventions contributed to rupture? & $\begin{array}{l}\text { Search for ending the impasse as promptly as possible through patient control and untimely } \\
\text { confrontation }\end{array}$ \\
\hline $\begin{array}{l}\text { What are the patient's predispositions that combined } \\
\text { with the therapeutic intervention, contributed to rupture }\end{array}$ & $\begin{array}{l}\text { Intensity of affects, lack of maturity to understand dynamic complex relationships, demand } \\
\text { for authenticity from therapist }\end{array}$ \\
\hline $\begin{array}{l}\text { What are the effects of rupture on therapists, patients } \\
\text { and/or therapeutic relationships }\end{array}$ & $\begin{array}{l}\text { Intense affections of fear, anguish and confusion in therapists and patients, patients feel that } \\
\text { their therapists cannot contain them }\end{array}$ \\
\hline
\end{tabular}


always telling him 'you have to behave, you cannot hit your parents" - Therapist 4.

The initial lack of trust could play a relevant role in the early origin of ruptures at a time when, as proposed by the interviewees, finding a purpose to attend psychotherapy is critical: "...adolescents come to therapy not because they want...this is the first obstacle (laugh) that is produced in the process with them ... to build a relationship and to be like mmm give meaning to what we will do in therapy, that is meaningful for them" - Therapist 3.

According to the interviewees, resolving these initial difficulties could favor the strengthening of the adolescent's confidence towards the clinician, leading to gradually injecting meaning to the engagement in therapy; understanding the space as a favorable environment for introspection and the expression of personal ideas.

Some interviewees identify an aspect that can lead to ruptures and impact the bond created at early stages of therapy: the implicit adolescent expectation of loyalty from the therapist, which if not addressed in the therapeutic work can negatively impact the therapeutic alliance, this highlights the importance of clarifying the therapist's role. In the following vignette a therapist narrates a rupture episode that emerged in the context of community based program from the need of breaching confidentiality based on the potential risk to others: the adolescent disclosed a situation where he did put in danger another person's life: "The first sessions with this boy...he did not want to talk, he was very angry...he felt that I betrayed him...he told me 'Dude, I trusted you, and you told my dad. 'I repeated that I was compelled to do it, that as a community program we could not be accomplices of something like that...that I said it to him before he told me about the whole situation" - Therapist 5.

It is important to point out that like the bond development, the therapeutic space, its boundaries and agreements could be vulnerable and should not be considered completed since the adolescent and therapist may need to review them over and over again especially during the ruptures: "The therapeutic space suddenly ceased to be a healthy space, ceased to be a hundred percent reliable space, it began to be a representative space of a system which he does not feel part of, a system that somehow does not solve his difficulties... when indeed, to protect himself from this ambivalence that the therapeutic situation generates, he says...basically it does not matter what this space is like, I do not need this space" - Therapist 1 (Table 4).

\section{When the family hinders the therapeutic process}

A distinct aspect about adolescents, which has even been deemed as a difficulty by some therapists, lies on their dependence on caregivers, whom not only tend to request the intervention but also pay for it and can decide unilaterally the early therapy termination. One interviewee says: "I think that this can be a disadvantage, that there is no...independence in general...not even economically, obviously, because the processes are paid by the parents, or the caregivers" - Therapist 8.

The inclusion of the family becomes a therapeutic objective to consider and consequently there is need to establish an alliance with them and the promotion of their participation in the therapeutic process; as Therapist 5 points out: "I see it more as a disadvantage in some specific cases, in that they depend on a caregiver. Why? Especially here at school, because it is very complex when the caregiver does not come, it is much more complex to intervene. I feel that in the intervention with adolescents...the process obviously needs to be global, considering the context of the family."

The caregiver's participation in therapy can originate ruptures between the therapist and the adolescents when they reject their presence in the therapeutic space understood as individual. Alternatively, rupture could happen if the therapeutic objectives are incompatible with those of the caregivers'. The following vignette illustrates an example of this: "He sent me a WhatsApp message and told me that this therapy was no longer serving him and that he came here because of other personal needs, that he did not come to talk to his family and he felt very exposed by them, he felt that they criticized him...he said that this was not being well handled in the last few sessions...I was not serving him for what he needed"- Therapist 7.

The therapists' lack of attention on the need to motivate the family to be part of the process, and the explanation of the roles that both have, can lead to the

Table 4. The therapeutic boundaries as an articulator of the purpose of therapy.

\begin{tabular}{|c|c|}
\hline Guiding questions & Themes \\
\hline Which therapeutic attitudes contributed to rupture? & Lack of awareness about the adolescent's assumptions towards the therapeutic framework \\
\hline Which therapeutic interventions contributed to rupture? & Difficulty to encourage therapeutic purpose, lack of clarification of the therapist's role \\
\hline $\begin{array}{l}\text { What are the patient's predispositions that combined } \\
\text { with the therapeutic intervention, contributed to rupture }\end{array}$ & $\begin{array}{l}\text { Lack of personal motivation to initiate a process of psychotherapy, mistrust of the therapist's } \\
\text { abilities, negative expectations towards therapy perceived as a controlling space, demand of } \\
\text { loyalty from the therapist }\end{array}$ \\
\hline $\begin{array}{l}\text { What are the effects of rupture on therapists, patients } \\
\text { and/or therapeutic relationships }\end{array}$ & $\begin{array}{l}\text { Patient's mistrust in the therapeutic space, impossibility of establishing a collaborative } \\
\text { therapeutic bond }\end{array}$ \\
\hline
\end{tabular}


maintenance or emergence of expectations that move away from the limits of psychotherapy, being also a source for disagreements that can even lead to a drop-out. A specific manifestation of this, which tends to be recurring among the interviewees, has to do with the pressure that caregivers place on clinicians for quick and observable results in adolescents. In the following vignette, a therapist points to this element as a cause of a patient dropping out: "I think I was pushed into meeting the goals in less time, also because... at times did not progress as I expected or as the mother demanded...or as she requested" - Therapist 6. Similarly, another therapist refers: "The scarce visibility of the psychologist as a real support figure for children...that, I think, is a disadvantage, the fact that one has to be constantly validating one's work, showing that this is part of a process, that this has a purpose...to show indicators of progress, so that families or parents also get to see...the evolution or the real impact of the process" - Therapist 3.

Even when the family does not actively and directly participate in the psychotherapeutic process, the interviewed clinicians reported their pressure on both, therapists and adolescents, turning the family into a third party with symbolic presence during therapy. The interviewee comments: "there were other eyes in there, weren't there?... it was not a private space, it was not only the both of us there". Ruptures can emerge indirectly, not through direct disagreements, but by the influence on the adolescent motivation through the devaluation of the clinician. In the following example, a therapist talks about the disagreement's effects with the patient's caregiver:

"I feel that from then on, the teenager, well, clearly assumes another attitude, basically less receptive... less collaborative...um....and I link this to that episode. He never made it explicit to me, he never said to me: 'What happens is that my aunt is telling me this...', but...she probably heard things about me, negative judgments from the caregiver, and that influenced the way she treated me" - Therapist 8.

Another way in which ruptures with the family system is presented in therapy is through the triangulation of young people, which creates ambivalent feelings on them: "The mother told me that the girl said there were certain things about the therapy she disagreed with. So...this is like an... annoyed mom there, because deep down, what she says it is that...there were certain things that I told her, that the teenager felt as an attack on her mother... which is probably related to family dynamics...so the next session was very complicated; it was complicated because...uh...because the girl was trapped in a network of loyalties... and she was probably looking at me as part of that network"- Therapist 1.

While facing these situations, some therapists take rivalry positions or attitudes towards family members or take pseudo-parental roles. One interviewee refers to this role as "a savior" and says: "I think that it is a recurring feeling when working with teenagers...uh...this feeling that the parents...uh...boycott the relationship with your coup...emm ... your patient, and it is easy to get involved in a competitive relationship with parents...I think there is something going on there...this 'I'm going to be a good father to you, adolescent'... uh... and I think it made me a bit angry there, I think that maybe it was one of the difficult things we had to handle, that I was angry because it happened after so much work." - Therapist 2 (Table 5).

\section{Discussion and Conclusions}

This study has sought to account for common elements of therapy with adolescent's ruptures based on therapists' experience and to identify the therapeutic scenarios in which they emerged. The identified four categories are discussed below based on their clinical relevance in the therapeutic work with adolescents.

A phenomenon called "failure to recognize adolescent experience" has been described, as referring to the clinicians' ability to be sensitive to their patients' needs. Interviewees emphasis the importance of being sensitive more than being empathetic towards the adolescents' need during therapy. Sensitivity has been widely used in the field of early intervention and is known to assist secure attachment development. A sensitive caregiver has the ability to be aware of the infant's signals and to act accordingly towards them (Ainsworth, Bell, \& Stayton, 1971). Subsequently, Meins, Fernyhough, Fradley, and Tuckey (2001) further developed this concept understanding sensitivity, as the ability to "have the child mind in mind"

Table 5. When the family hinders the therapeutic process.

\begin{tabular}{|c|c|}
\hline Guiding questions & Themes \\
\hline Which therapeutic attitudes contributed to rupture? & Assumption of a "more competent caregiver" role \\
\hline Which therapeutic interventions contributed to rupture? & No clarity about the role of each participant in the therapy; rivalry with the family \\
\hline $\begin{array}{l}\text { What are the patient's predispositions that combined } \\
\text { with the therapeutic intervention, contributed to rupture }\end{array}$ & $\begin{array}{l}\text { Caregivers' influence on the therapeutic process; incompatibility of adolescent/caregiver } \\
\text { reasons for consultation; adolescents refusing their caregivers' participation; caregivers' } \\
\text { expectations for rapid therapeutic results; symbolic caregivers' presence }\end{array}$ \\
\hline $\begin{array}{l}\text { What are the effects of rupture on therapists, patients } \\
\text { and/or therapeutic relationships }\end{array}$ & Therapist-adolescent-caregivers triangulation; adolescents' negative predisposition to therapy \\
\hline
\end{tabular}


and coining the concept of mind-mindedness. In the case of this study, the use of this concept by interviewees contributes to the recognition of the complexity of the adolescents' evolutive stage, and accounts for the challenge of being sensitive in a therapeutic context while understanding and establishing a therapeutic relationship with another being who is rapidly developing at an emotionally, social and cognitive level. The concept of mindmindedness demands the therapist to keeps "constantly in mind the patient's mind". In this regard, in recent years, some authors have proposed that mentalization could play a relevant role in explaining what happens during rupture in terms of relationships (Morken, Karterud \& Arefjord, 2014) and could be a focus during therapists' training and supervision (Levendosky \& Hopwood, 2017). Authors such as Binder et al. (2008) point out that many adolescents who are in therapy may have deficits in their ability to reflect upon themselves and others and, therefore, in their capacity for abstract thinking. That's why interventions in which therapists ask their clients to reflect on complex issues such as family dynamics, can become a source of ruptures insofar as they require the use of structural functions that are still under development which can also be interfered with by directly addressing issues that are difficult to talk about because of their emotional load or simply because they do not understand them.

On the other hand, this concept has been used in cultural psychology to account for how the therapists' competencies in order to understand and adapt to culturally-diverse racial, linguistic, ethnic and sexual contexts, among others (Cardemil \& Battle, 2003; Sue, 2006; Sue \& Zane, 2009). In this study, the interviewees remind us of adolescence as a social, historical and culturally-situated developmental stage (Duro, 2005), therefore, clinicians are challenged to establish a relationship with a complex subject who belongs to a subculture with particular, constantly changing interests, values and beliefs.

The distal sources of rupture are multiple external agents that could influence the therapy with adolescents; in this study, the family is highlighted as the main tangled web of ecologically related subsystems that do so Therefore, the clinician's illusion of being in an exclusively dual relationship while in therapy with adolescents, opens a blind spot regarding agents that can contribute to ruptures and that may have more influence than the consultant on the course of the therapy.

When the focus is placed on the therapist's, it is possible to observe the use of controlling strategies with adolescent patients. This is a transversal element of the emerging themes. Although this aspect is not exclusive to interventions with young people, it is important to point out that child and adolescent areas have been characterized by the presence of adult-centered views, which historically have excluded girls, boys and adolescents and have tended to position adults as experts (Silva, 2013). This is also recognized in the psychotherapy field (Castillo-García,
Castillejos-Zenteno, \& Macias-Esparza, 2017) whenever it is evident that there is "an experienced adult" who asymmetrically faces an "underaged person who is still in a developing stage into a moment in life when they will be able to fully integrate socially and to be respected" (UNICEF, 2013). As observed in the interviewees' discourse, this asymmetric view coexists with, but is not integrated into a children's rights perspective. This is made explicit in several vignettes that account for the clinician's duty of care while working with adolescents.

This disparity of views is manifested in controlling actions and the adoption of parental roles towards the adolescent based on a misunderstood children rights protection framework; in these interventions the young person is considered an object instead of a subject of protection, resulting in ruptures where the therapists perceive themselves as the sole responsible.

Finally, another aspect regarding therapeutic context and therapeutic boundaries that is relevant for the understanding of the phenomena of ruptures is that interviewees agree with ideas found in the literature describing patients who do not see themselves as needing treatment and families who don't understand the role they play during it (Bolton Oetzel \& Scherer, 2003; Dakof, Tejeda, \& Liddle, 2001). This requires the clinician explicitly establish and talk about the limits of therapy as one of the fundamental tasks of the therapeutic work with adolescents and their families; this is indeed a complex task, considering the need to establish a sufficiently flexible and open framework that is democratically co-constructed and redefined throughout the process by its vicissitudes. At an early therapeutic stage the contracting aim is to establish clear boundaries about the context, roles and responsibilities with regards to the task on hand. The principle is to empower the adolescent without compromising their safety; this continues throughout the therapeutic process (Herreman, 2015). This led interviewed clinicians to rethink the implications for diverse therapeutic settings (the clinical box, the consultants' home, the cyberspace by means of virtual communication) and diverse therapeutic resources (letters, journals and other written, symbolic resources), that can be used to address issues difficult for adolescents to speak about, given the intensity in which feelings may be experienced.

Even though this study provides useful results in the field of psychotherapy, it has some limitations. The first is the use of interviews to collect data. Although the interviews sought to emotionally place the interviewees in the situation of rupture and its context, their testimonies relied mostly on their recollections; memory may be interfered by the passage of time, and by memory processing based on their own theoretical conceptualizations. In this regard, it is necessary to promote studies that incorporate methods of direct observation of ruptures with adolescents in psychotherapy.

A second point to keep in mind is the sample compo- 
sition, since the participation of cognitive-behavioral therapists was omitted, leaving out a widely recommended approach for working with adolescents. This omission is a product of the way in which the participants were recruited; having four pairs of therapists from different approaches was the priority and a proposal of possible theoretical perspectives was not considered a priori. As soon as four therapists were recruited, and their approach was identified, a second therapist to match each of the four initial interviewees' therapeutic approach was recruited to complete each pair. In addition, it is important to consider that each participant's therapeutic approach may have effects on how to deal with ruptures. Due to the exploratory nature of this study, this was not analyzed, but should be considered in further studies.

Finally, we consider important to acknowledge that the results of this study are based on the therapists' narrative. In order to deepen the understanding of ruptures in psychotherapy with adolescents, is necessary to do a further study/research that includes the adolescents view point recollection of a rupture.

Despite the limitations described above, we believe this work is relevant for various reasons. Firstly, it evidences the need to incorporate a special focus on the phenomena of rupture in the intervention with adolescents, an aspect that has been especially recommended in the work with adults (Castonguay, Boswell, Constantino, Goldfried, \& Hill, 2010) but not so in the work with teenagers; in light of what has been stated by the interviewees, rupture is a critical element in the work with adolescents. Secondly, the results led us to adopt an ecological viewpoint in the attempt to understand the complexity of interventions with adolescents; this viewpoint considers both, individual and evolutionary aspects, as well as contextual and historical-political elements that depict adolescents and therapists' perspectives about themselves. And thirdly, this study led us to consider the clinical relevance of contracting, sensitivity, and mentalization on the potential origin of ruptures in order to specifically understand this phenomenon in a deeper and relational way and, broadly, further understand the therapeutic relationship and the process of building the therapeutic alliance. Such consideration leads us to consider not just the explicit, but the unconscious mutual influence aspects of adolescent psychotherapy since a rupture always enacts transference-countertransference aspects of the therapeutic relationship (Safran \& Muran, 2006).

\section{References}

Achenbach, T. M., McConaughy, S. H., \& Howell, C. T. (1987). Child/adolescent behavioral and emotional problems: implications of cross-informant correlations for situational specificity. Psychological Bulletin, 101(2), 213.

Ainsworth, M. D. S., Bell, S. M., \& Stayton, D. J. (1971). Individual differences in Strange Situation behavior of one-year olds. In H. R. Schaffer (Ed.), The origins of human social relations. New York: Academic Press.

Binder, P. E., Holgersen, H., \& Nielsen, G. H. (2008). Establishing a bond that works: a qualitative study of how psychotherapists make contact with adolescent patients. European Journal of Psychotherapy and Counselling, 10(1), 55-69.

Binder, P. E., Moltu, C., Hummelsund, D., Sagen, S. H., \& Holgersen, H. (2011). Meeting an adult ally on the way out into the world: Adolescent patients' experiences of useful psychotherapeutic ways of working at an age when independence really matters. Psychotherapy Research, 21(5), 554-566.

Bhola, P., \& Kapur, M. (2013). The development and role of the therapeutic alliance in supportive psychotherapy with adolescents. Psychological Studies, 58(3), 207-215.

Bolton Oetzel, K., \& Scherer, D. G. (2003). Therapeutic engagement with adolescents in psychotherapy. Psychotherapy: Theory, Research, Practice, Training, 40(3), 215.

Cardemil, E. V., \& Battle, C. L. (2003). Guess who's coming to therapy? Getting comfortable with conversations about race and ethnicity in psychotherapy. Professional Psychology: Research and Practice, 34(3), 278.

Castillo-García, M. T., Castillejos-Zenteno, L., \& Macias-Esparza, L. K. (2017). El reto de incluir a niños y niñas en las sesiones de Terapia Familiar. Revista REDES, 35.

Castonguay, L. G., Boswell, J. F., Constantino, M. J., Goldfried, M. R., \& Hill, C. E. (2010). Training implications of harmful effects of psychological treatments. American Psychologist, 65(1), 34 .

Dakof, A., Tejeda, M., \& Liddle, A. (2001). Predictors of engagement in adolescent drug abuse treatment. Journal of the American Academy of Child and Adolescent Psychiatry, 40, 274-281.

Duro, E. (2005). Adolescencias y políticas públicas. De la invisibilidad a la necesaria centralidad. M. Krichesky (Comp.). Adolescencia e inclusión educativa. Buenos Aires: Noveduc, OEI, UNICEF, Fundación SeS.

Daly, A. M., Llewelyn, S., McDougall, E., \& Chanen, A. M. (2010). Rupture resolution in cognitive analytic therapy for adolescents with borderline personality disorder. Psychology and Psychotherapy: Theory, Research and Practice, 83(3), 273-288.

Delgado, S., Strawn, J.R., Pedapati, E. (2015). Contemporary Psychodynamic Psychotherapy for Children and Adolescents: Integrating Intersubjectivity and Neuroscience. Heidelberg: Springer.

DiGiuseppe, R., Linscott, J., \& Jilton, R. (1996). Developing the therapeutic alliance in child-adolescent psychotherapy. Applied and Preventive Psychology, 5(2), 85-100.

Eubanks-Carter, C. F., Muran, J. C., \& Safran, J. D. (2014). Rupture resolution rating system (3RS): Manual. New York: Beth Israel Medical Center.

Gelo, O. C., Pritz, A., \& Rieken, B. (2015). Psychotherapy research. Foundations, Process and Outcome. Wien: Springer.

Gersh, E., Hulbert, C. A., McKechnie, B., Ramadan, R., Worotniuk, T., \& Chanen, A. M. (2017). Alliance rupture and repair processes and therapeutic change in youth with borderline personality disorder. Psychology and Psychotherapy: Theory, Research and Practice, 90(1), 84-104.

Hawley, K. M., \& Weisz, J. R. (2003). Child, parent and therapist (dis)agreement on target problems in outpatient therapy: The therapist's dilemma and its implications. Journal of Consulting and Clinical Psychology, 71(1), 62. 
Herreman, Ch. (2015). La triple postura: herramientas para reestablecer la seguridad en comunidades, familias y personas. Ciudad de México: Fundación pro niños de la calle.

Horvath, A. O. (2016). Emerging trends in psychotherapy process research [Tendencias emergentes en la investigación del proceso psicoterapéutico]. Estudios de Psicología, 37(23), 226-259.

Horvath, A. O., \& Bedi, R. P. (2002). The alliance. In C. Norcross (Ed.), Psychotherapy relationships that work: Therapist contributions and responsiveness to patients (pp. 37-69). New York: Oxford University Press.

Horvath, A. O., Del Re, A. C., Flückiger, C., \& Symonds, D. (2011). Alliance in individual psychotherapy. Psychotherapy (Chic), 48 (1), 9-16.

Krause, M., Altimir, C., \& Horvath, A. (2011). Deconstructing the therapeutic alliance: Reflections on the underlying dimensions of the concept. Clinica y Salud, 22(3).

Lambert, M. J. (2013). Bergin and Garfield's handbook of psychotherapy and behavior change. Hoboken, NJ, US: John Wiley \& Sons Inc.

Levendosky, A. A., \& Hopwood, C. J. (2017). A clinical science approach to training first year clinicians to navigate therapeutic relationships. Journal of Psychotherapy Integration, 27(2), 153.

Maurel, M. (2009). The explicitation interview: examples and applications. Journal of Consciousness Studies, 16(10-11), 58-89.

Meins, E., Fernyhough, C., Fradley, E., \& Tuckey, M. (2001). Rethinking maternal sensitivity: Mothers' comments on infants' mental processes predict security of attachment at 12 months. The Journal of Child Psychology and Psychiatry and Allied Disciplines, 42(5), 637-648.

Morken, K., Karterud, S., \& Arefjord, N. (2014). Transforming disorganized attachment through mentalization-based treatment. Journal of Contemporary Psychotherapy, 44(2), $117-126$

Pietkiewicz, I., \& Smith, J. A. (2014). A practical guide to using interpretative phenomenological analysis in qualitative research psychology. Psychological Journal, 20(1), 7-14.

Roth, A., \& Fonagy, P. (2013). What works for whom? a critical review of psychotherapy research. New York: Guilford Press.

Safran, J. D. (1993). Breaches in the therapeutic alliance: An arena for negotiating authentic relatedness. Psychotherapy: Theory, Research, Practice, Training, 30(1), 11.

Safran, J. D., \& Muran, J. C. (1996). The resolution of ruptures in the therapeutic alliance. Journal of Consulting and Clinical Psychology, 64(3), 447.

Safran, J. D., \& Muran, J. C. (2000). Negotiating the therapeutic alliance: A relational treatment guide. New York: Guilford Press.

Safran, J. \& Muran, C. (2006). Has the concept of the therapeutic alliance outlived its usefulness? Psychotherapy: Theory, Research, Practice, Training, 43 (3), 286-291.
Safran, J. D., Muran, J. C., \& Eubanks-Carter, C. (2011). Repairing alliance ruptures. Psychotherapy, 48(1), 80.

Safran, J. D., Muran, J. C., \& Samstag, L. W. (1994). Resolving therapeutic alliance ruptures: A task analytic investigation. In A. O. Horvath \& L. S. Greenberg (Eds.), Wiley series on personality processes. The working alliance: Theory, research, and practice (pp. 225-255). Oxford, England: John Wiley \& Sons.

Shirk, S. R., Karver, M. S., \& Brown, R. (2011). The alliance in child and adolescent psychotherapy. Psychotherapy (Chic), 48(1), 17-24.

Silva, I. (2013). Políticas públicas de infancia y adolescencia: una mirada desde el bienestar subjetivo y los procesos participativos. V Congreso Internacional de Investigación y Práctica Profesional en Psicología. Facultad de Psicología, Universidad de Buenos Aires, Buenos Aires. Buenos Aires: University of Buenos Aires.

Smith, J.A., Flowers, P., Larkin, M. (2009). Interpretative phenomenological analysis: theory, method, research. London: Sage.

Steinberg, L., Dahl, R., Keating, D., Kupfer, D. J., Masten, A. S., \& Pine, D. S. (2006). The study of developmental psychopathology in adolescence: Integrating affective neuroscience with the study of context. In D. Cicchetti \& D. J. Cohen (Eds.), Developmental psychopathology: Developmental neuroscience (pp. 710-741). Hoboken, NJ, US: John Wiley \& Sons Inc.

Sue, S. (2006). Cultural competency: From philosophy to research and practice. Journal of Community Psychology, 34(2), 237-245.

Sue, S., \& Zane, N. (1987). The role of culture and cultural techniques in psychotherapy: A critique and reformulation. American Psychologist, 42(1), 37.

Sue, S., Zane, N., Nagayama Hall, G. C., \& Berger, L. K. (2009). The case for cultural competency in psychotherapeutic interventions. Annual Review of Psychology, 60, 525-548.

Turpin, G., Barley, V., Beail, N., Scaife, J., Slade, P., Smith, J.A., \& Walsh, S. (1997). Standards for research projects and theses involving qualitative methods: suggested guidelines for trainees and courses. Clinical Psychology Forum, 108, 3-7.

Weitkamp, K., Klein, E., Hofmann, H., Wiegand-Grefe, S., \& Midgley, N. (2017). Therapy expectations of adolescents with depression entering psychodynamic psychotherapy: A qualitative study. Journal of Infant, Child, and Adolescent Psychotherapy, 16(1), 93-105.

Wilson, M., \& Sperlinger, D. (2004). Dropping out or dropping in? A re-examination of the concept of dropouts using qualitative methodology. Psychoanalytic Psychotherapy, 18 (2), 220-237.

Unicef. (2013). Superando el adultocentrismo. Serie Participación Adolescente Ahora, Cuadernillo, 4. Available from: unicef.cl/web/.../UNICEF-04-SuperandoelAdultocentrismo.pdf 